\title{
The Impact of Workplace Bullying and Harassment on Employee Turnover in Banking Industry of Pakistan.
}

\author{
RABIA INAM KHAN \\ Lecturers, Bacha Khan University, Charsadda \\ rabia.khan138@live.com \\ MUHAMMAD NISAR KHAN \\ Lecturers, Bacha Khan University, Charsadda \\ nisarmgt@bkuc.edu.pk \\ IHTESHAM KHAN \\ Assistant Professor, Abdul Wali Kahn University, Mardan \\ ihtishamkhan@awkum.edu.pk
}

\begin{abstract}
This study has been executed with intent to find out the impact of workplace bullying and harassment on employees' turnover among the bankers. Qualitative data was gathered through in-depth interviews from 50 bankers. Non- probability sampling technique was adopted. In this research study, the researcher has used the principle of purposive sampling. The results depict that bankers are being bullied but they do not want to leave their organizations due to bullying. There are many other factors that make them think to leave organization such as extreme stress, work burden and better opportunities for work. The results also revealed that employees who are being harassed do not disclose such incidents. This paper contains a message for the senior management of organizations to review their bullying and harassment policies. Moreover, this study suggests that there can be other factors that can be the reason for employee turnover.
\end{abstract}

Keywords- Bullying, harassment, bankers, employee turnover, workplace.

\section{Introduction}

In today's turbulent work environment, the utilization and management of the organizational resources is a challenge for the organizations. Among all the resources an organization encloses, human resources are of paramount importance. Human resources are considered as a nucleus of an organization, responsible for carrying out daily operations. Thus, they are known as the wholly and solely source of competitive advantage. The performance of employees in any industry, specifically in service industry, can bring an exclusive rebellion and can be a foundation of phenomenal growth in organizations. Contemporary organizations are facing challenge in attracting and retaining their most precious asset i.e. Human resources. In order to attract and retain the talented workforce, organizations need to ensure that their policies and procedures are transparent. 
They need to create such an environment that is ideal and healthy and free of all those acts and behaviors that makes it hostile and unpleasant for the employees. Among the organizational issues, workplace bullying and harassment are two critical issues which can negatively impact employee performance and ultimately organizational productivity. Workplace bullying is also referred to as workplace abuse. It involves those actions which can hurt, intimidate, humiliate and threaten others. Bullying may be verbal, physical or psychological, According to Davoudi et al. (2013), bullying behaviors have an impact on employees' satisfaction as well. Workplace harassment is defined as dehumanizing, commenting or discouraging an individual.. It may also involve unwanted and unwelcomed sexual favors and relationships. These two issues are like a cancer which can harm the employees and organizations as well.

Workplace bullying and harassment involve such actions that become overt with the passage of time and create an unethical and hostile environment. With the expansion of economy, gradually diversification and difficulty of social life, bullying and harassment issues come into play. From a global perspective, majority of the countries have formed laws and legislations to make it clear that harassment and bullying are crimes and the perpetrators are given severe punishments. Organizations should take initiatives to eradicate such unfavorable practices. Organizations need to recognize the causes behind bullying and harassment so that they can prevent employee turnover and can create a more responsive and ideal workplace. Bullying and harassment policies should be embedded in the culture of the organization and every employee should be educated that bullying and harassment of any member will not be tolerated at any cost. Employees should be aware of acceptable and unacceptable workplace behaviors in order to make a healthy and constructive workplace.

\subsection{Research Objectives}

This study has been conducted with an intention to inspect bullying and harassment in service industry of Pakistan. The following have been set as the objectives of this research:

- To study and analyze the increasing ratio of bullying and harassment incidents at workplace.

- To elaborate the problems which are being faced by the victims of bullying and harassment.

- To examine the relationship of workplace bullying and harassment with employee turnover.

\section{Literature Review}

\subsection{Employee Turnover}

For the effective and efficient functioning and operations of an organization, employee turnover can be a critical issue and it creates negative impact on the working of the organization. According to Cho et al.(2009) turnover intentions mean that someone has the intention to leave his organization for which he is working for, that shows the end of relationship between employee and that organization. Hellman (1997) explains turnover intentions as the behavioral intentions revealing the intention of an individual to leave the organization. Whereas Hom and Griffeth (1995) said that a conscious voluntary 
permanent withdrawal of an individual from an organization can be referred as employee turnover. Organizations invest millions and billions in selecting, training and motivating their employees and when these employees leave the organization then it becomes an issue for the organizations to find new employees and reinvest in them. In this case, organizations cannot attain their objectives and they cannot save their costs (Waldman, Kelly, Arora \& Smith, 2004). Due to this loss in productivity and output, researchers are paying more attention to identify and uncover those factors that drive employee turnover. The consequences of these studies have revealed that employee turnover or intentions to leave a workplace has direct relation with job stressors (Podsakof \& LePine, 2007). One reason of voluntary turnovers is that it distress managers and employees think that the managers will consider that the employees who are going to leave organization will have better skills and abilities than those who are not going to leave because they have no other option than their existing job (Tanova \& Holtom, 2008; Nadiri \& Tanova, 2010).

\subsection{Workplace Bullying}

Workplace bullying has no universal definition. Every researcher defines this concept with a little disparity. Hutchinson et al., (2008) are of the view that workplace bullying involves ruthless actions that are sometimes veiled and are often hard to demonstrate. Perpetrators or bullies intend to persistently sabotage their targets through different behaviors including hurting someone verbally or mentally, embarrassing someone, humiliating, ignoring and putting down people. These behaviors often escalate with the passage of time (Smith, 2011, cited in Davoudi et al., 2013). According to Salin and Hoel (2011) workplace bullying consist of frequent and repetitive behaviors of organizational individuals aimed at other individuals with an intention to hurt, threaten, degrade, frighten, weaken or demoralize them. It might include health and safety risks to the employees. The act of bullying frequently occurs in those organizations where hierarchical relationships are present i.e. organizations where people have reporting or supervisory relationships. Generally, perpetrators show covert behaviors, which with the passage of time become overt. They tend to exhibit such actions which are harmful for the employees as well as the organization (Di Martino, Hoel and Cooper, 2003). The antecedents of workplace bullying might include organizational hierarchies, organizational culture and structure and job design and job requirements (Salin, 2004).

In addition to these factors, some other factors such as increasing turbulence and competition, globalization, downsizing are contributing in cultivating a work environment where bullying is becoming common (Sheehan, 2006 as cited in Ayodeji, 2011). Researchers suggest that all the definitions of workplace bullying have two vital points. Firstly, bullying behaviors are unrelenting in nature. They occur again and again. Einarsen et al. (2003) stressed that bullying actions take place on weekly basis (Bowling \& Beehr, 2006). Bullying behavior often involves certain actions: argumentative or irritable behavior (Zapf, 1999), scattering hateful rumors (Rayner, 1997); e-mails containing malicious information (Baruch, 2004); and physical abuse (Einarsen, 1999). Pate and Beaumont (2009) are of the view that senior management of any organization can play a crucial role in implementing such policies which reduce bullying and harassment behaviors in organizations. These intimidating and daunting behaviors, if not 
controlled, can be very costly for the organizations and can result in employee stress and employee turnover. Takaki et al. (2013) concluded that workplace bullying and harassment behaviors cause headache, inflexibility of muscles and some other types of pains in human body. These behaviors are a source of pain for human body. Workplace bullying is like a cancer and has unfavorable and unpleasant consequences for the target and the organization as well. Researchers are of the view that when perpetrators humiliate, degrade or hurt someone verbally or physically then it lowers the self esteem of the person being targeted (Mathiesen \& Einarsen, 2007).

These humiliating and ruthless behaviors are also a vital source of producing some serious psychological diseases for example misery, depression, anxiety, trauma, helplessness etc (Mathiesen \& Einarsen, 2004; Mikkelsen \& Einarsen, 2002). Constantino et al. (2006) stressed that bullying at workplace has pervasive and extensive effects on the productivity of the organization and employees with low self esteem become an obstacle in achieving organizational goals and objectives. Those who are the victims of bullying show low interest in contextual performance. Farmer (2011) advocated that according to a survey conducted in 2010 every one employee out of three is the victim of bullying. This survey was conducted by the Workplace Bullying Institute situated in USA. Among the many job stressors, workplace bullying is one of the major sources of stress at job and its relation with the intention to leave has been investigated by many researchers (Djurkovic, McCormack \& Casimir, 2008; Nishii \& Mayer, 2009). Ocel and Aydin (2012) advocated that intentions to turnover and workplace bullying are positively correlated.

\subsection{Workplace Harassment}

An unwanted behavior linked with a significant protected attribute, which is the effect of or purpose of violating an individual's self-respect or creating a threatening, unfriendly, demeaning, mortifying or odious environment for that individual can be termed as harassment (Acas, 2010). An employer should explain their employee about the behavior which is unacceptable in their organization by giving examples such as:

- Degrading someone on the basis of age, sex, sexual orientation, race, religion or belief and disability and spreading nasty rumors.

- Replicating memos which are decisive about someone to a person who has no need to know

- Scorning or humiliating someone

- Omission or persecution

- Inequitable action

- Arrogant supervision or wrong use of position and power.

- Unwanted sexual advances such as standing too close, asking for sexual favors, touching, display of offensive materials, decision making on the basis of sexual advances being accepted or rejected.

- Without organization order threatening or commenting someone about job security.

- Intentionally discouraging a competent worker by overburden and continuous criticism

- Put a stop on individual's progress by purposely blocking training opportunities or promotion (Acas, 2010). 
According to Hass (2004) Workplace harassment has an effect not only on the individuals who are directly involved but also impacts on customer, self-esteem, productivity, employee retention and business. In 2003, the monetary benefits totaled over \$236Min which sexual harassment payments alone reaching \$50M paid by EEOC. $\$ 50 \mathrm{M}$ is a huge amount which can be used in business operations. But that is not the end, attorney and mediation costs as well as the business loss due to the headlines impact on customers and clients are not included in these figures but it can be prevented. To prevent this you should start with the 3 key elements that is a clear policy, a fully committed management team and an educated workforce to avoid harassment in workplace. If you have these 3 elements the rest will come naturally.

According to David (n.d.), to deal with harassment complaints is not easy. This occurs because of the misunderstanding that exists between 'intent' and 'impact'. 'Intent' is the source motive or intention to affront or hurt other when initiating an action. Whereas 'Impact' refers to the ways in which a person is negatively impacted by the Source's behavior without his intention. The study of Merkin (2008) supported that those employees who are experiencing workplace sexual harassment has a greater turnover intentions than those who are not experiencing this. Sims et al. (2005) stressed that increase turnover can be the result of number of experiences of harassment by an employee even after you have controlled organizational commitment, job satisfaction and marital status.

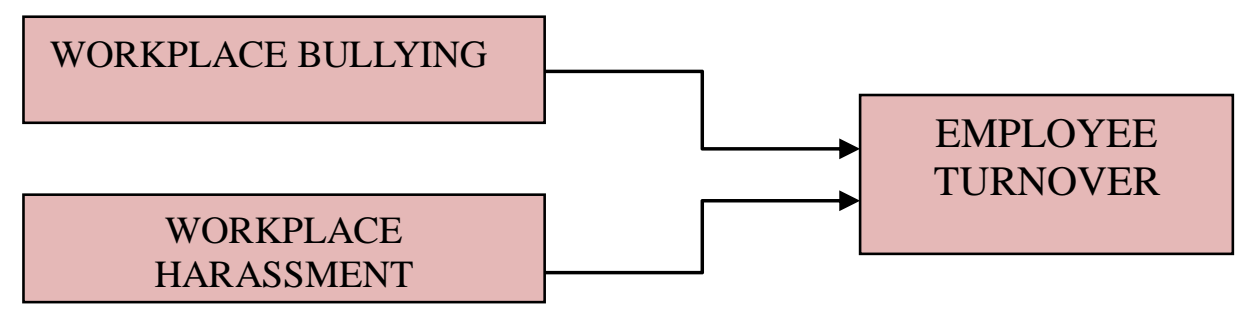

\section{Research Methodology \\ 3.1 Research Design}

Figure 1: Conceptual Framework

As this study was conducted with an aim of gaining insights and explaining the problem so we opted exploratory research. As Zikmund (2003), explained that exploratory studies are executed when researchers do not have detailed information about any issue or they have little or no initial information about the particular problem. Exploratory research helps researchers to investigate and clearly define the nature of problem. According to Sekaran and Bougie (2010) exploratory study is conducted when we lack sufficient information. So, for obtaining rigorous results the researcher has conducted exploratory research.

\subsection{Research Tool}

For the purpose of data collection, qualitative technique has been used. In-depth interviews were conducted from 10 respondents. These respondents were from different 
banks. In this research study, the researcher has used the principle of purposive sampling. In this type of sampling Researcher only contacts those people who they think can provide required information (Zikmund, 2003). The interview questions were being adopted from an already conducted research "Workplace Bullying and Employee Turnover Intentions among Iranian Employees" (Seyed Mehdi Mousavi Davoudi, Kiarash Fartash, Meysam Allahyari, Hamidreza Yarahmadi, 2013). A series of questions were asked from different interviewees' working presently in different banks.

\section{Finding and Discussion}

Interviews were conducted from 50 respondents and their responses were analyzed by using content analysis technique. The first question which was being asked from the respondents was: Is there persistent criticism of work and effort? The majority of the respondents said that people always criticize work of their colleagues in the workplace.

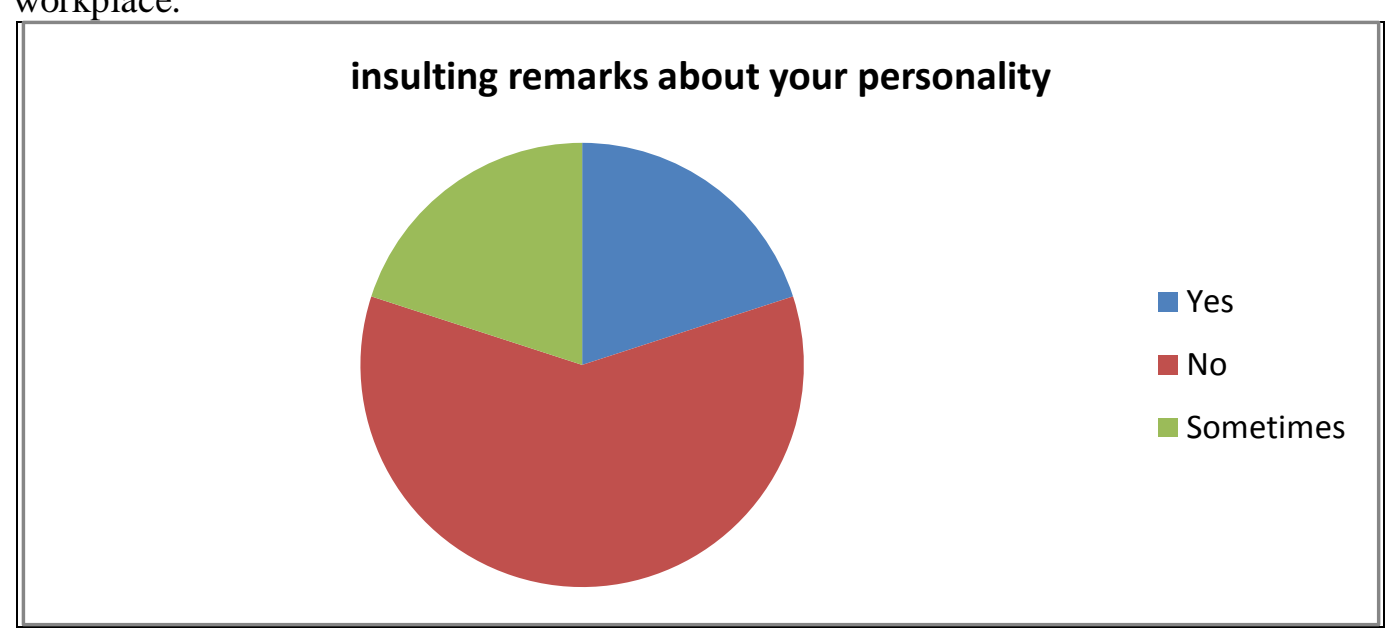

The second question which was being asked was "Having insulting or offensive remarks made about your personality (i.e. habits or background), your attitude or your personal life." According to the majority of respondents there were no insulting remarks about personality and habits. One of the respondent said that "nobody is allowed to make negative or offensive remarks about someone's personality or personal habits. If someone does so, he has to face the music because of the disciplinary policies of the bank." Employees have the right to make complaint through a legal way. 


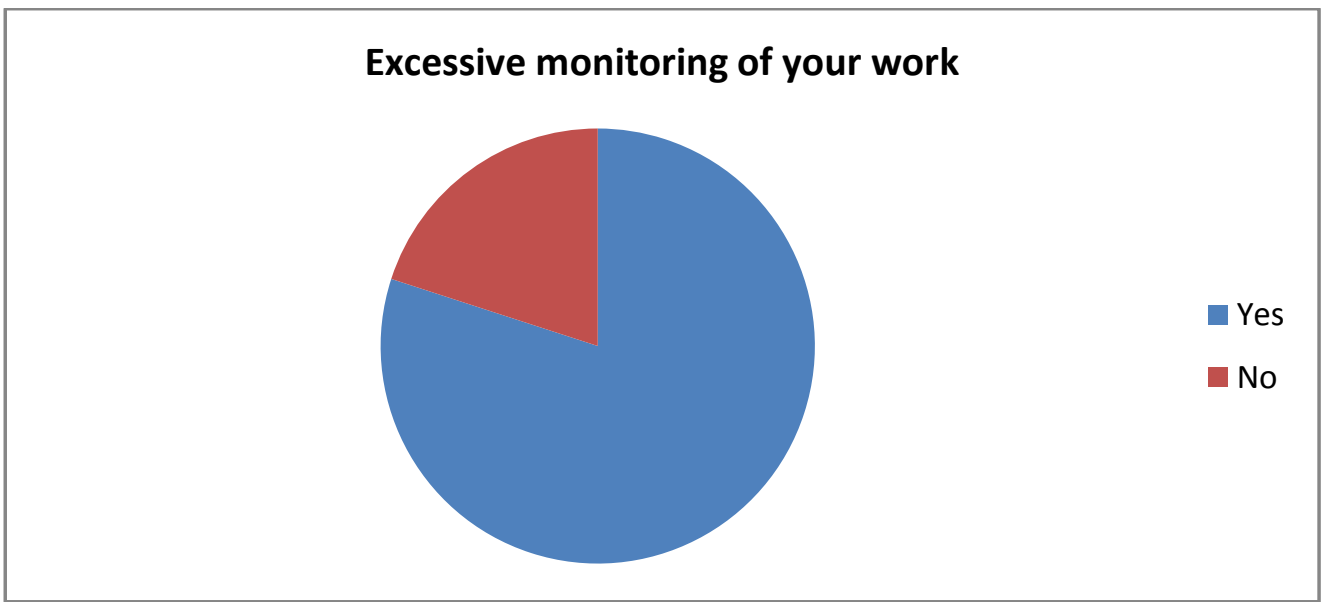

The third question related to bullying was "Excessive monitoring of your work?"The responses of majority of the respondents showed that their work is being monitored by their immediate managers. One of the respondent answered that there is continuous monitoring of our work due to the relative appraisal system. Our performance is compared with that of others. So for performance development, our work is monitored on daily basis.

\section{Spreading of gossips and rumors}

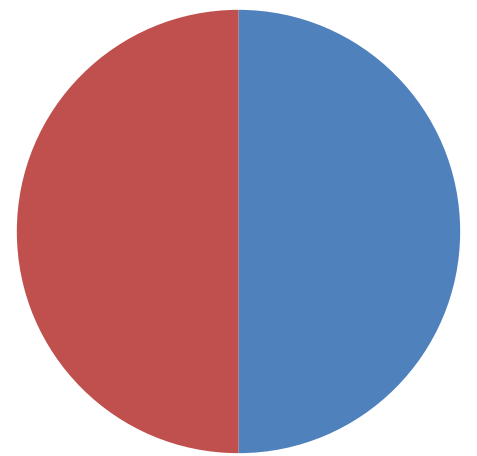

The fourth question which was being asked was "Spreading of gossips and rumors about you ". The responses to this question were mixed. Some said that people spread gossips while others were of the view that we are so much over burdened with work that we don't have time to bother about such issues. One of the respondent said that employees of one department spread rumors about employees of other department. According to one employee "I am working in credit department. Employees of operations department say that credit managers do not do any task and they sit idle whole day". In this way they try to give negative remarks about employees of other departments and other branches. 


\section{I often think about quitting my job}

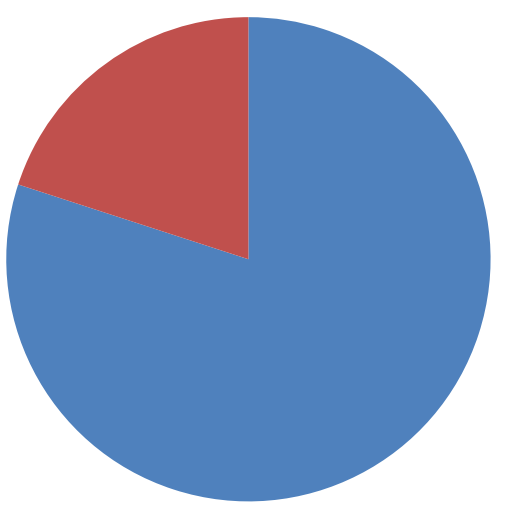

The next question which was being asked from the respondents about turnover was "I often think about quitting my organization". Majority of the respondents agreed with the statement. One of the respondent replied that "Every individual wants better opportunity for work and everyone seeks for better jobs and more salaries." One of the respondent said that "Yes I often think of quitting my job but not due to bullying, but because I want profession change."

In response to a question "I sometimes look for a new job" the majority of the respondents said that they are looking for a better option. One of the respondent said "I want career development. There is no career development in banking sector. So I want some better opportunity". One of the respondent said "there is no concept of payment of overtime in banking industry. We do not get bonuses either. So I am searching for a new job." One of the newly hired respondent said that "I cannot switch to a new job as switching jobs leaves a negative impression of an individual."

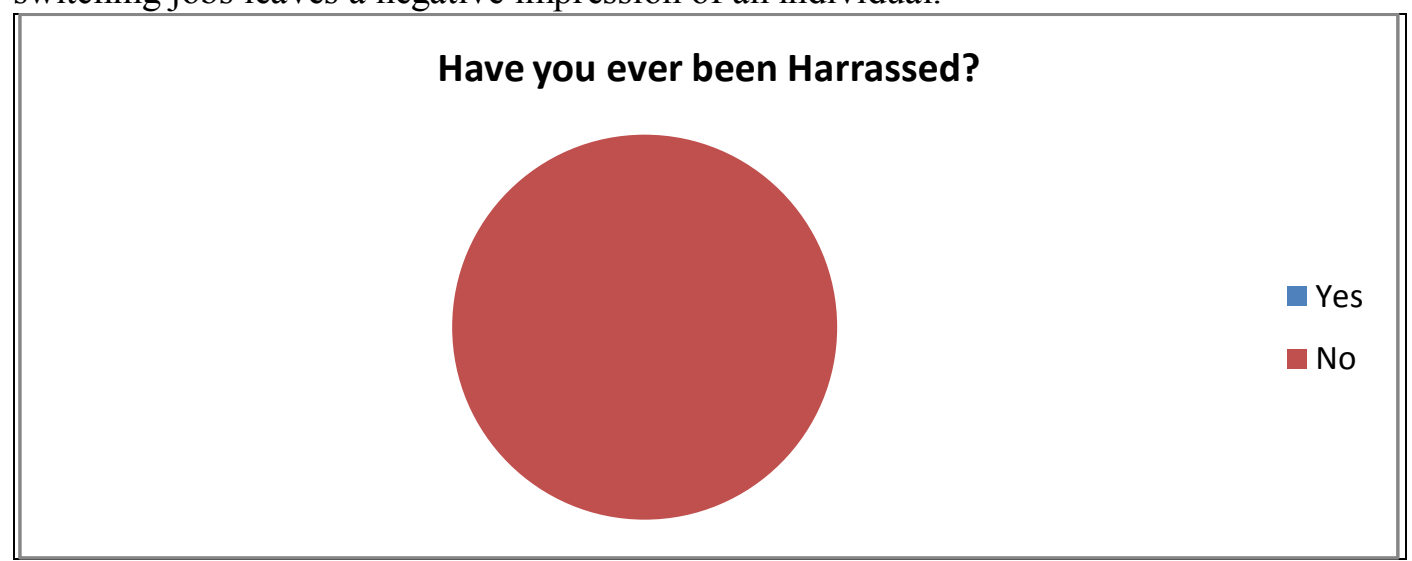

The next question which was being asked from the interviewees was "Have you ever been harassed? "In response to this question, all the respondents said they were not being harassed. According to one of the respondent "People in our culture feel reluctant 
to tell such incidents. They feel embarrassment while sharing harassment incidents so they do not tell the truth". According to one of the employee mostly lower level females are harassed by their bosses.

\section{Conclusion}

The results of the study depict that employees' in banking sector often think of leaving their organizations. The reasons for their turnover intensions are many. These reasons may include excessive work, overtime, and fewer career developments. Employees said that bullying is so much common in our society that we don't bother about it much. Employees' were of the view that they want to leave organizations but not due to being bullied rather they want to avail better career opportunities. Though employee bullying creates mental and physical stress but due to the increasing ratio of unemployment people do not quit their job. They quit their job when they get a better opportunity to work with a higher salary and more perks. However no cases have been reported of the harassment. Employees said that there are less cases of harassment. People who are being harassed do not disclose such cases because our culture does not permit such unethical activities and people who are the victim of harassment are also considered culprits.

\subsection{Limitations}

Despite the incontrovertible significance of the findings, this study has two limitations. Firstly, the results of the study are confined to few employees only. It cannot be generalized to all the employees of banking industry as we chose a limited number of employees for conducting interviews. Secondly, there can be many other factors that can be a reason for employee turnover in banking sector. These few limitations can be avoided in the future to get a more lucid picture of employee bullying and harassment and turnover.

\section{References}

Acas. (2010). Retrieved from Acas website: www.acas.org.uk.

Baruch, Y. (2004). Bullying via e-mail. Information \& Management, Vol. 42(2), pp. 36171.

Bowling, N. A. \& Beehr, T. A. (2006). Workplace harassment from the victim's perspective: a theoretical model and meta-analysis. Journal of Applied Psychology, Vol. 91, pp. 998-1012.

Cho, S., Johanson, M. M., \& Guchait, P., (2009). Employees intent to leave: a comparison of determinants of intent to leave versus intent to stay. International Journal of Hospitality Management 28(3), 374-381.

David, F. (2011). Workplace Bullying: An increasing epidemic creating traumatic experiences for targets of workplace bullying, International Journal of Humanities and Social Science Vol. 1(7) [Special Issue -June 2011]

David, S. B. (n.d.). Employee Assistance Program Association of Toronto (EAPAT). Retrieved from Employee Assistance Program Association of Toronto (EAPAT) website: http://www.eapat.org/ 
Di Martino, V., Hoel, H. \& Cooper, C. (2003). Preventing Violence and Harassment in the workplace, European Foundation for the improvement of living and working conditions. www.eurofound.eu.int .(Assessed 10 July 2007).

Djurkovic, N., McCormack, D., \& Casimir, G. (2008). Workplace bullying and intention to leave: the moderating effect of perceived organizational support. Human Resource Management Journal, 18(4), 405-422. DOI: 10.1111/j.17488583.2008.00081.x

Einarsen, S. (1999). The nature and causes of bullying at work. International Journal of Manpower, Vol. 20, pp. 16-27.

Einarsen, S. \& Mikkelsen, E. G. (2003). Individual effects of exposure to bullying at work. in Einarsen, S., Hoel, H., Zapf, D. and Cooper, C.L. (Eds), Bullying and Emotional Abuse in the Workplace. International Perspectives in Research and Practice, Taylor and Francis, London, pp. 127-44.

Hatem, Ö. \& Orhan, A. (2012).Workplace Bullying and Turnover Intention: The Moderating Role of Belief in a Just World. International Journal of Business and Social Science Vol. 3 No. 13; July 2012.

Haas, N. A. (2004). Workplace Harassment Affects Us All. The News-Times, Dec. 2004.

Hellman, C. M. (1997). Job satisfaction and intent to leave. Journal of Social Psychology, 137(6): 67-689.

Hom, P. W. \& Griffeth, R. W. (1995). Employee turnover. South Western College Publishing, Cincinnati, $\mathrm{OH}$.

Hutchinson, M., Jackson, D., Wilkes, L., \& Vickers, M. (2008). A new model of bullying in the nursing workplace: Organizational characteristics as critical antecedents. Advances in Nursing Science, 31(2): 60-71.

Jiro T. T. T. \& Kumi, H. (2013). Associations of Workplace Bullying and Harassment with Pain, International Journal of Environmental Research and Public Health 2013, 10, 4560-4570; doi:10.3390/ijerph10104560.

Judy, P. \& Phillip, B. (2009). Bullying and harassment: a case of success? Employee Relations, Vol. 32 ( 2), 2010 pp. 171-183.Emerald Group Publishing Limited.

Matthiesen, S. B. \& Einarsen, S. (2001). MMPI-2 configurations among victims of bullying at work. Europen Journal of Work and Organizational Psychology, 10(4),467-484.doi:10.1080/13594320143000753

Matthiesen, S. B. \& Einarsen, S. (2004). Psychiatric distress and symptoms of PTSD among victims of bullying at work. British Journal of Guidance and Councelling, 32(3), 335-356. doi:10.1080/03069880410001723558

Matthiesen, S. B., \& Einarsen, S. (2007). Perpetrators and targets of bullying at work: role stres and individual differences. Violence and Victims, 22(6), 735-753.doi: http://dx.doi.org/10.1891/088667007782793174.

Merkin, R. S. (2008). The Impact of Sexual Harassment on Turnover Intentions, Absenteeism, and Job Satisfaction:Findings from Argentina, Brazil and Chile. Journal of International Women's Studies:10(2) , 73-91. 
Nadiri, H. \&Tanova, C. (2010). An investigation of the role of justice in turnover intentions, job satisfaction, and organizational citizenship behavior in hospitality industry. International Journal of Hospitality Management, 29, pp. 33-41.

Nishii, L. H. \& Mayer, D. M. (2009). Do inclusive leaders help to reduce turnover in diverse groups? The moderating role of leader-member exchange in the diversity to turnover relationship. Journal of Applied Psychology, 94(6), 1412-1426. doi: $10.1037 / \mathrm{a} 0017190$

Oluwakemi, A. (2011). Exploring Workplace Bullying in a Para-Military Organisation (PMO) in the UK: A Qualitative Study. International Business Research Vol. 4(2).

Podsakoff, N. P., LePine, J. A. \& LePine, M. A. (2007). Differential challenge stressorhindrance stressor relationships with job attitudes, turnover intentions, turnover, and withdrawal behavior: A meta-analysis. Journal of Applied Psychology, 92(2), 438-454. doi:10.1037/0021-9010.92.2.438.

Rayner, C. (1997). The incidence of workplace bullying. Journal of Community and Applied Social Psychology, Vol. 7(3), pp. 199-208.

Salin, D. (2004). Organizational Measures against Workplace Bullying: The View of Business Professionals. Paper presented at the 4th International Conferences on Bullying and Harassment in the Workplace. 28-29 June, Bergen.

Salin, D. \& Hoel, H. (2011). Organisational causes of workplace bullying. In Einarsen, S., Hoel, H., Zapf, D., \& Cooper, C. (Eds). Workplace bullying: Development in theory, research and practice. London. Taylor \& Francis, 227-243.

Sheehan, M. (2006). The Fight at Eureka Stockade: Down with the Tyrant an' Bully, A paper presented at the Inaugural Professorial Lecture, Glamorgan Business School.

Sims, C. S., Drasgow, F., \& Fitzgerald, L. F. (2005). The Effects of Sexual Harassment on Turnover in the Military: Time-Dependent Modeling. Journal of Applied Psychology:90(6), 1141-1152.

Smith, J. (2011). Bullying in the Nursing Workplace: A Study of Perioperative Nurses. A Dissertation of the Degree PHD of Management, UNIVERSITY OF PHOENIX.

Tanova, C., Holtom, B. (2008). Using job embeddedness factors to explain voluntary turnover in four European countries. The International Journal of Human Resource Management, 19(9): 1553-1568.

Waldman, J., Kelly, F., Arora, S., \& Smith, H. (2004). The shocking cost of turnover in health care. Health Care Management Review, 29(1), 2-7.

William, G. Z. (2003). Business Research Methods, 7th Edition, Thomson Southwestern. Uma Sekaran and Roger Bougie, Research Methods for Business, $5^{\text {th }}$ edition 2010, Wiley.

Zapf, D. (1999). Organizational, work group related and personal causes of mobbing/bullying at work. International Journal of Manpower, Vol. 20, pp. 70-85 